\title{
The genetic causes of neurodegenerative diseases
}

\author{
John Hardy* \\ Neurogenetics Laboratories, Mayo Clinic \\ Jacksonville, FL, USA
}

With the application of molecular genetics, we are now beginning to understand the etiology and the early stages of pathogenesis of the major neurodegenerative diseases, including Alzheimer's disease, Parkinson's disease, Pick's disease and Progressive Supranuclear Palsy. Surprisingly, these studies are showing that these diseases share pathogenic mechanisms which involve tau or synuclein aggregation. In this article, I review the progress in the molecular genetic analysis of these major neurodegenerative diseases and discuss how they are related to each other.

\section{Introduction}

I started to work on Alzheimer's disease in 1979, largely by accident, in Newcastle, England. Newcastle was, at that time, and still, a center of Alzheimer's disease research. It was where Blessed, Tomlinson and Roth carried out their pioneering studies in the 60 s describing their discovery that Alzheimer's disease was the major cause of 'senility'. I worked in the MRC Demyelinating Unit under James Edwardson's direction and with Robert and Elaine Perry. Henry Wisniewski had been Director there until 1977 and had, for a time, combined directing the MRC Unit with directing the Staten Island group. His energy and drive was legendary and the technical staff spoke of him with awe. Stories abounded of him spending long nights, after flying from New York, working on the electron microscope. His passion, at that time, was to characterize thoroughly, the neuritic plaque and to emphasize that this was not normal ageing and to eliminate the term 'senile' plaque. Wisniewski's work brought a rigor to a field which was, of necessity, purely de-

\footnotetext{
*Correspondence to: Neurogenetics Laboratories, Birdsall Building, Mayo Clinic, Jacksonville, FL 32224, USA. E-mail: hardy@ mayo.edu.
}

scriptive at that time. In 1979, there were only perhaps 10 groups working on Alzheimer's disease worldwide: Wisniewski's, Terry's in the US, Kidd, the Newcastle group and Bowen and Davison in England and Gottfries and Winblad in Sweden. The field was struggling to find acceptance as worthy of study since studying normal aging was thought to be a waste of time and resources.

That political fight was won, and we now understand much about the etiology and pathogenesis of Alzheimer's disease and other neurodegenerative disease: instead of descriptive work, we now understand these prevalent and distressing diseases as processes and are able to carry out deterministic experiments to try and understand the disease processes more thoroughly. Of greatest importance is that we are now on the verge of being able to treat these diseases because of our understanding of the mechanisms of the early stages of pathogenesis. This progress has come out about largely because of the success of the application of the techniques of molecular genetics. In this chapter, I summarize this progress.

The genetic lesions underlying many of the autosomal dominant forms of Alzheimer's disease, prion diseases and Parkinson's disease and frontal temporal dementia have been discovered (see Table 1 for a summary of the pathology of these disorders). Surprisingly, it has become evident that these diseases share pathogenic pathways.

\section{Alzheimer's disease}

Mutations in three genes have been shown to cause autosomal dominant Alzheimer's disease: the amyloid protein precursor gene $(\mathrm{A} \beta \mathrm{PP})[10]$, the presenilin 1 (PS1) gene [33] and the presenilin 2 (PS2) gene [24].

\subsection{Mutations in the A $\beta P P$ gene}

The pathogenic mutations in the $\mathrm{A} \beta \mathrm{PP}$ gene are shown in Fig. 1 (see http://www.alzforum.org/members/ 
Table 1

The pathology of human neurodegenerative disease

Alzheimer's disease

Prion disease

FTDP-17/Pick's disease

Parkinson's disease/Lewy body dementia

Progressive supranuclear palsy and corticobasal degeneration

Multiple system atuophy plaques $(\mathrm{A} \beta)$, tangles $\beta 4$ - and 3-repeat tau) and often, Lewy bodies ( $\alpha$-synuclein) often PrP plaques; sometimes tangles (4- and 3-repeat tau); sometimes Lewy bodies tangles (4- or both 4- and 3-repeat tau) or Pick bodies (3-repeat tau)

Lewy bodies

tangles; mainly consisting of 4-repeat tau

oligodendroglial synuclein inclusions

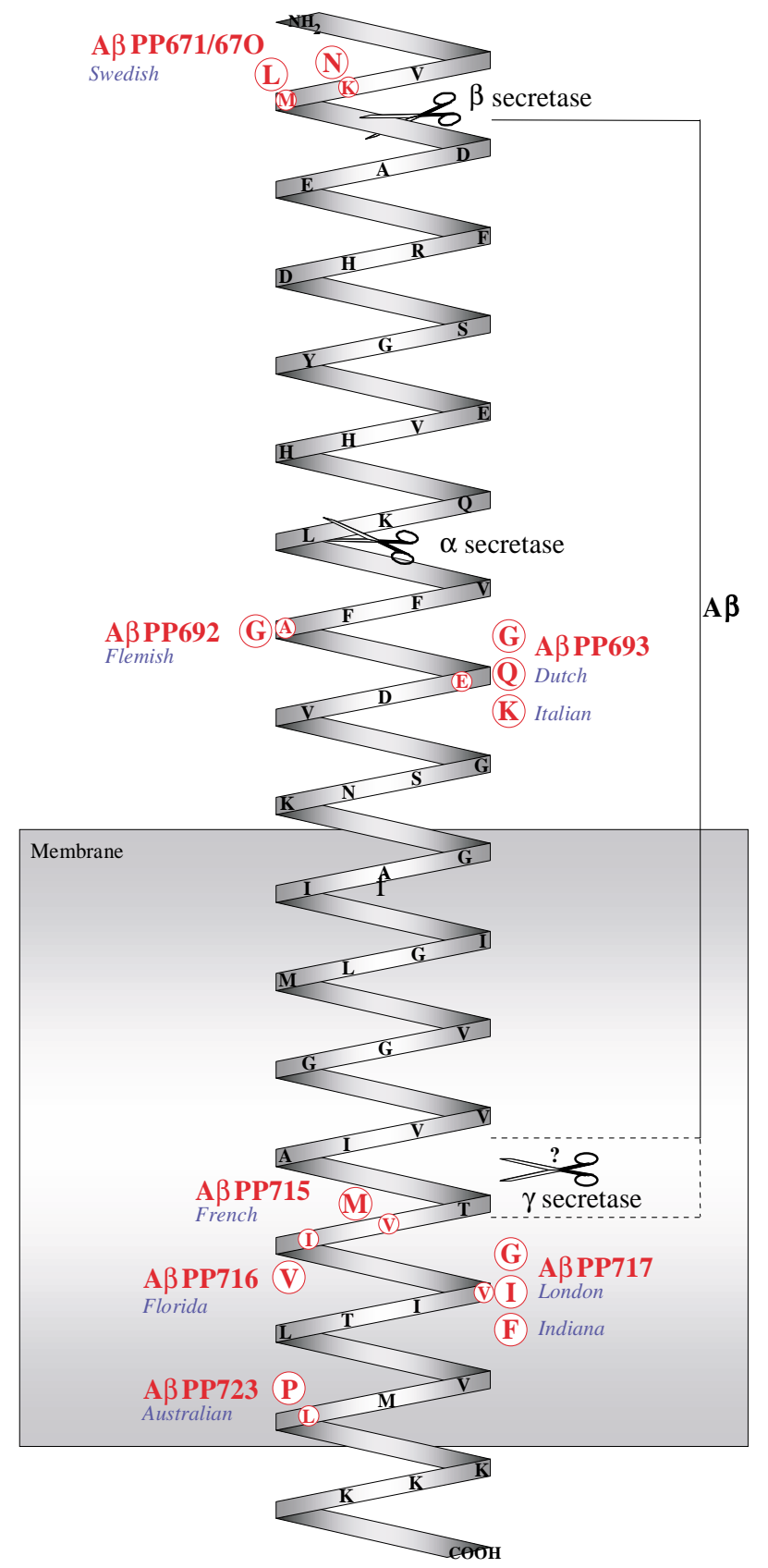

Fig. 1. Amyloid $\beta$ protein precursor. Pathogenic mutations in the $\mathrm{A} \beta \mathrm{PP}$ gene in relation to the sites of cleavage of this molecule. 


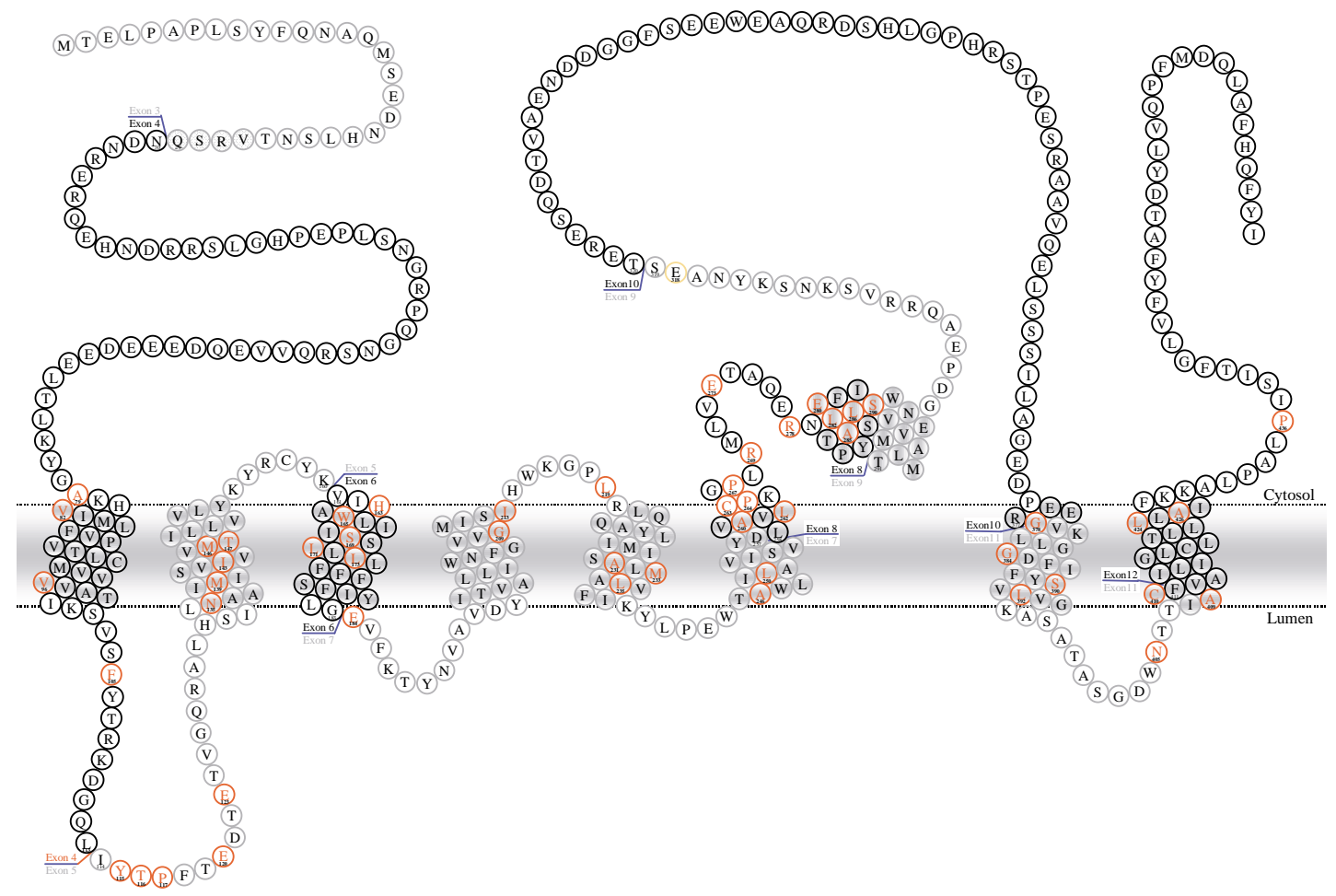

Fig. 2. Presenilin 1. Pathogenic missense mutations in the presenilin 1 protein (in red) drawn on the likely topographic representation of this molecule. Not shown are the deletion and insertion mutations.

resources/app_mutations/index.html for references). Of note is the fact that the mutations cluster around the sites of processing of the $\mathrm{A} \beta \mathrm{PP}$ molecule and all the mutations have as an outcome that a more depositable fragment of $\mathrm{A} \beta$ is released [35]. Most cases with $\mathrm{A} \beta \mathrm{PP}$ mutations have typical $\mathrm{AD}$ with an onset age in the late 40 s to mid 50s, and with an onset age which is modulated by apolipoprotein E genotype [18]. The exceptions to this rule are E693G, the first mutation described in $\mathrm{A} \beta \mathrm{PP}$, which causes hereditary cerebral heamorrhage with amyloidosis-Dutch type, a disorder characterized by multiple strokes and deposition of $\mathrm{A} \beta$ only in blood vessels [23] and A692G [17] which is sometimes characterized by strokes and sometimes by a dementia phenotype [4].

\subsection{Mutations in the PS1 gene}

The pathogenic mutations in the PS1 gene are shown in Fig. 2 (see http://www.alzforum.org/members/resources/ps_mutations/index.html for references). Most PS1 mutations lead to typical Alzheimer's disease in a fully penetrant fashion with an onset age of 30-50: a few PS1 mutations are associated with an unusual variant of $\mathrm{AD}$ which is characterized by spastic paraparesis and by the occurrence of massive congophilic angiopathy and 'cotton wool' rather than neuritic plaques [5]. The onset ages of PS1 encoded AD are typically not modulated by apolipoprotein E genotype. All the mutations tested to date alter $\mathrm{A} \beta \mathrm{PP}$ processing such that more $\mathrm{A} \beta 42$ is produced [32]. Nearly all the mutations are missense mutations: the exceptions are the $\Delta 9 \mathrm{mu}$ tation (an in-frame deletion of exon 9) [26] or mutations which lead to the insertion or deletion of single amino acids (see website). Thus, all mutations maintain the overall structure of the presenilin protein. The most parsimonious explanation of these genetic data is that the mutations do not lead to a simple loss of function of presenilin because this would effectively be caused by frameshift or chain termination mutations, neither of which have been found. It would seem most likely that the mutations lead to disease either by a gain of function or by a causing a complex (and greater than $50 \%$ ) loss of function through, for example, a mechanism by which the mutant inactive protein displaces the active wildtype allele. In support of this latter notion are the observations that the mutant PS1 alleles fail to rescue the egl phenotype of the $\mathrm{C}$ elegans homologue of PS1, sel12: they are thus, loss of function alleles in this assay [22]: furthermore, a loss of function al- 


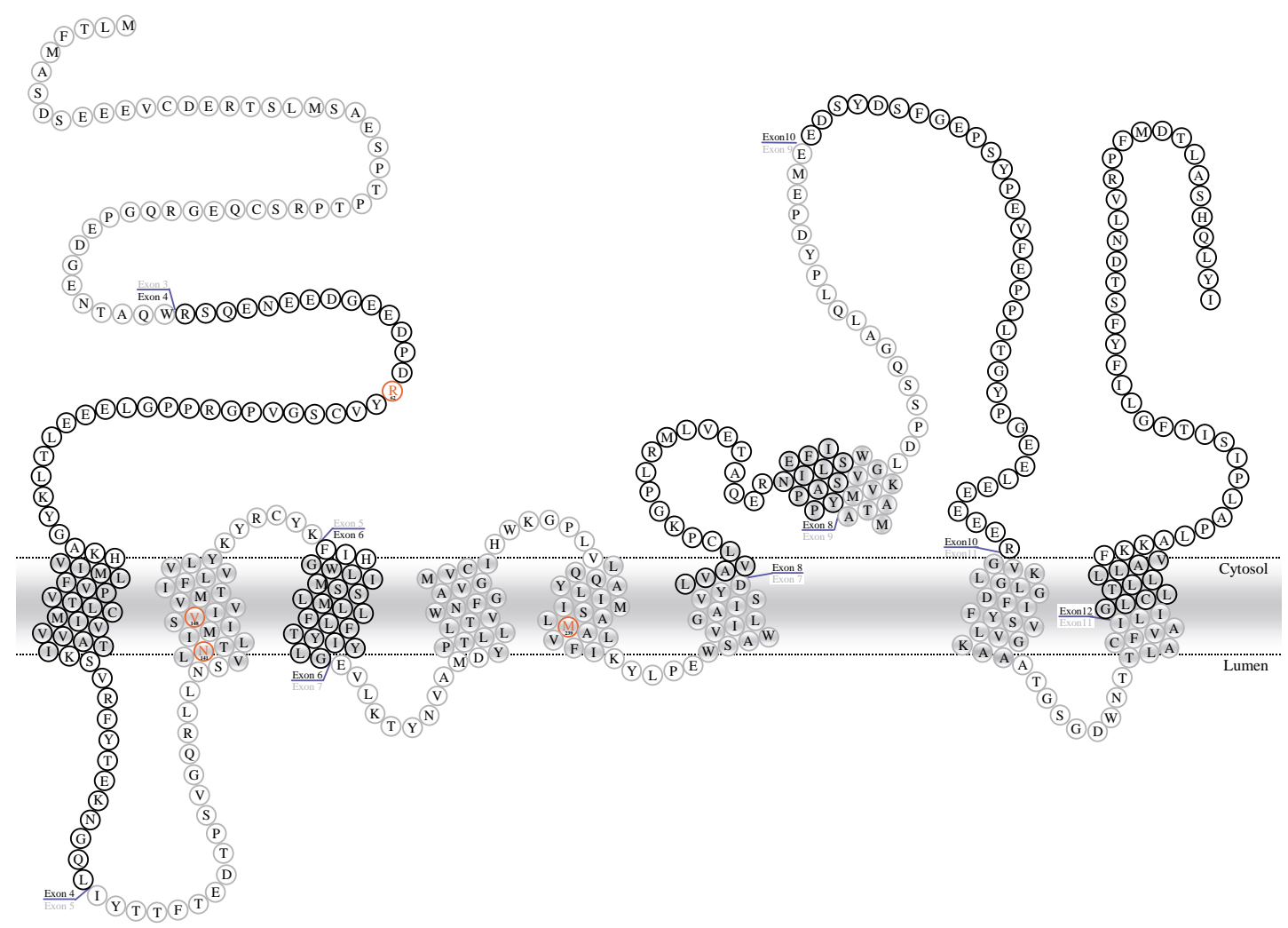

Fig. 3. Presenilin 2. Pathogenic missense mutations in the presenilin 2 protein (in red) drawn on the likely topographic representation of this molecule.

lele of sel12 affects A $\beta$ PP processing in the same way as pathogenic mutations [author's unpublished data]. Thus, it seems most likely that presenilin 1 mutations are loss of function mutations which lead to inactivation of the wildtype allele and lead to overall loss of function of between $50 \%$ and $99 \%$. In agreement with this suggestion have been antisense experiments in which downregulation of presenilin 1 leads to an increase in $\mathrm{A} \beta 42$ production in the same way as the pathogenic mutations [30]. Complete inactivation of PS1 in mice in which the gene is knocked out leads to halting of $\mathrm{A} \beta \mathrm{PP}$ processing at the $\gamma$-secretase point and to the build up of the $\mathrm{C}$-terminal fragment of $\mathrm{A} \beta \mathrm{PP}$ [6]. These and other data have led to the suggestion, now widely accepted, that the presenilins are $\gamma$-secretase [38].

\subsection{Mutations in the PS2 gene}

The pathogenic mutations in the PS2 gene are shown in Fig. 3 (see http://www.alzforum.org/members/resources/ps_mutations/index.html for references). Pathogenic PS2 mutations appear to have a very variable onset age, and in an individual family, the same mu- tation can lead to disease onsets as disparate as $\sim 40$ and $\sim 80$. The reason for this variability is not clear, although apolipoprotein E genotype does not appear to be a major determinant. Only three pathogenic PS2 mutations have been found, although there plausibly could be many others yet to be found, in individuals who have not been sequenced because they appear as 'sporadic' cases, or because they constitute a tiny percentage of late onset cases. Complete inactivation of the PS2 gene in PS2 knockout mice does not appear to have a large effect on $\mathrm{A} \beta \mathrm{PP}$ processing, suggesting that its role in $\mathrm{A} \beta \mathrm{PP}$ processing can be substituted for by PS1 [34].

\subsection{The effects of pathogenic mutations}

All of the mutations in A $\beta$ PP and in PS1 and PS2 which have been tested have been shown to affect $\mathrm{A} \beta \mathrm{PP}$ processing such that more $A \beta 42$ is produced [14]: these data are the intellectual underpinning of the amyloid cascade hypothesis (see Fig. 4). 


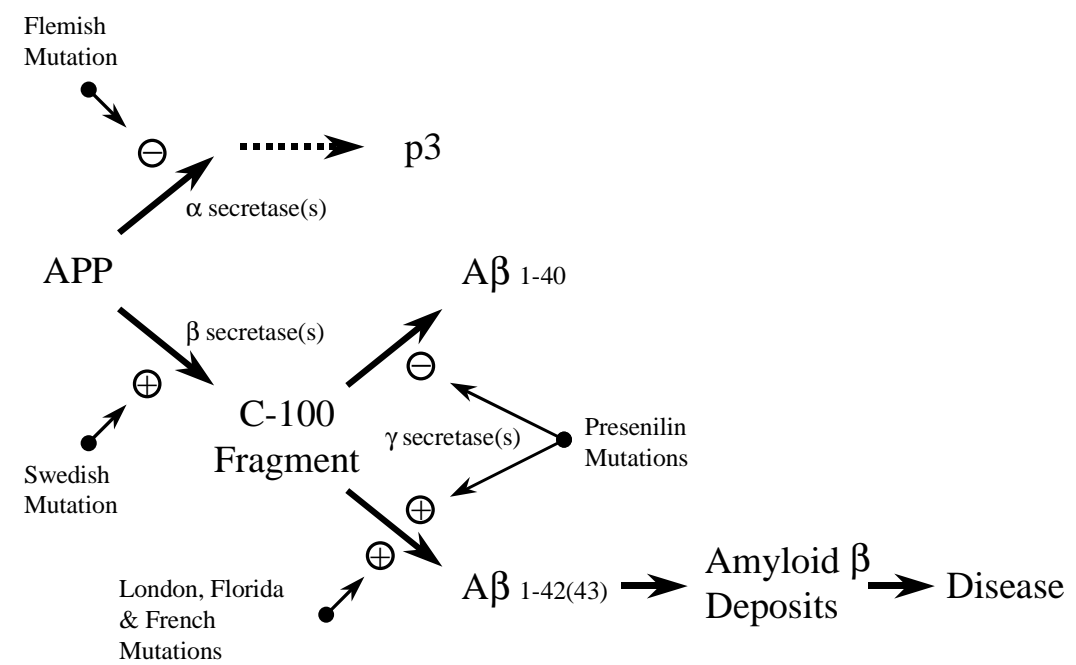

Fig. 4. The amyloid cascade hypothesis. Amyloid cascade hypothesis (adapted from [34]) showing the sites of the effects of the different pathogenic mutations shown in Figs 1-3.
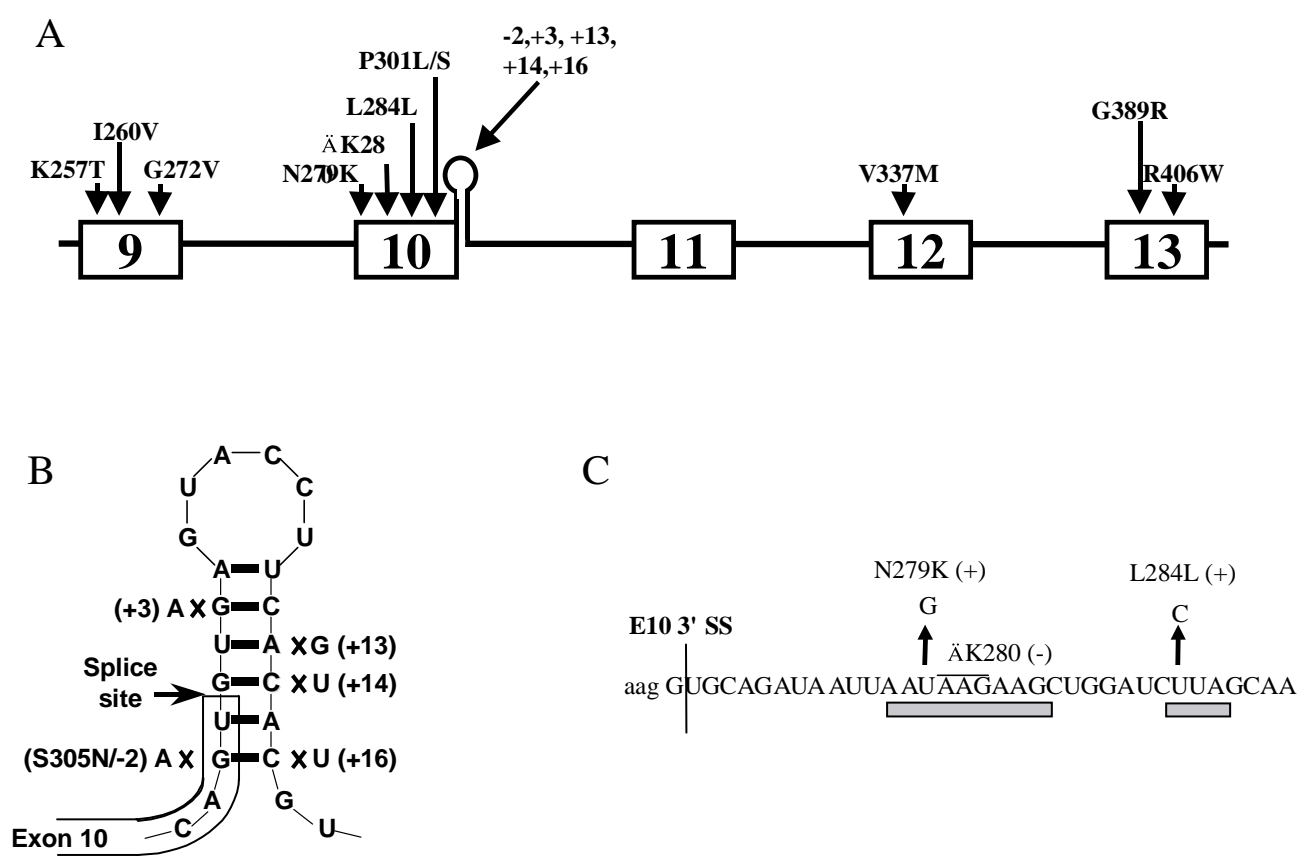

Fig. 5. Mutations in the tau gene, both in the open reading frame (A) and showing the positions which affect splicing alone at the stem loop structure (B) or affect both splicing and the open reading frame (C).

\subsection{The occurrence of Lewy bodies in Alzheimer's disease}

The occurrence of Lewy bodies in AD is well established [13]. Of particular note is the frequent occurrence of Lewy bodies in cases of $\mathrm{AD}$ with $\mathrm{A} \beta \mathrm{PP}$ and PS mutations $[21,25]$. These data suggest that Lewy bodies, like tangles, can be a secondary consequence of $\mathrm{A} \beta 42$ production.

\section{Tangles and Lewy bodies in prion diseases}

The genetics of prion diseases is outside the scope of this review: (see [29] and http://www.mad-cow.org/). 
41

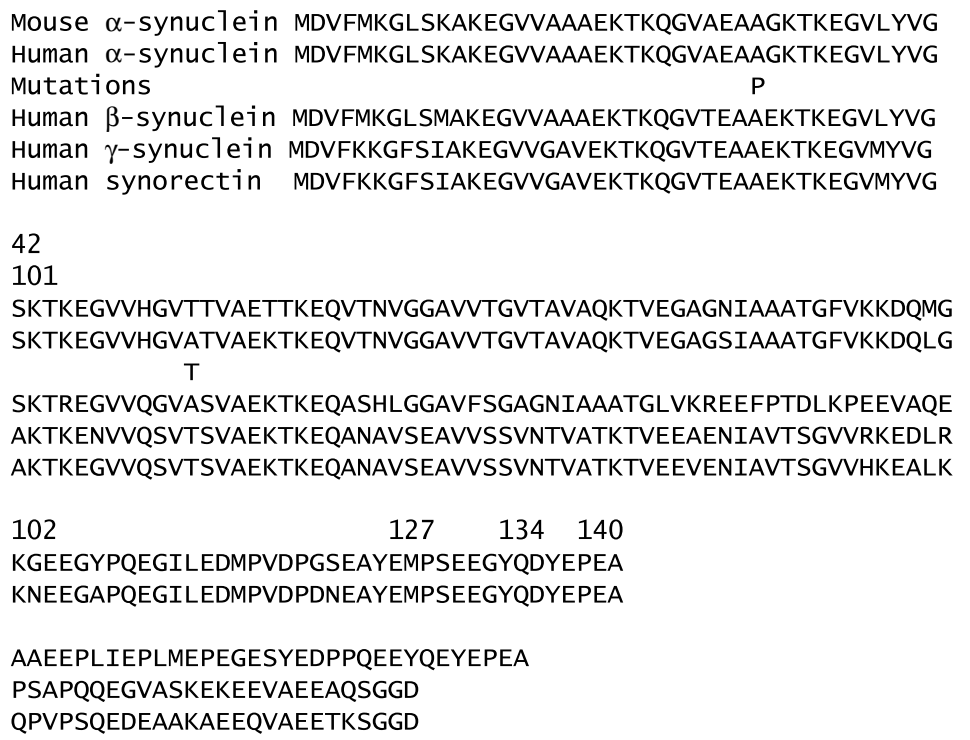

Fig. 6. Synuclein sequences and mutations. The sequences of the human synucleins and of mouse $\alpha$-synuclein: note that the better characterized human mutations (A53T) changes the human sequence to the rodent sequence at that residue.

However, of note is that several families with prion mutations, most notably the Indiana kindred, have neurofibrillary tangles identical to those found in Alzheimer's disease [9]. In addition the Indiana kindred has Lewy bodies [B. Ghetti, personal Communication]. Thus, both tau and $\alpha$-synuclein pathology can be downstream events to prion disease.

\section{Frontal-temporal dementia}

A large proportion of cases of frontal-temporal dementia are caused by mutations in the tau gene $[19,28]$. The pathogenic tau gene mutations are shown in Fig. 5 (see http://www.alzforum.org/members/research/tau/ tau_references.html). The tau mutations so far described all either affect the ratios of 3-repeat to 4-repeat tau by affecting the alternate splicing of exon 10 [12] or they occur in microtubule binding domains where they would be predicted to affect the microtubule binding of the tau protein. These data indicate that tau pathology can be caused as a direct consequence of mutations in tau [11] and show that this tau pathology can lead directly to neuronal loss and dementia [15].

\section{Progressive supranuclear palsy (PSP) and Corticobasal degeneration (CBD)}

Extensive tau sequencing has revealed that there are two ancestral tau haplotypes in the caucasian population [1]. The H1 (70\%) haplotype shows a robust association with the occurrence of both PSP and CBD: thus, the tau gene is a risk factor locus for both these diseases $([1,2], \mathrm{H}$. Houlden, personal communication).

\section{Parkinson's disease and lewy body dementia}

Two mutations in the synuclein gene have been described which cause familial Lewy body disease, A53T and A30P [20,27] (see Fig. 6): the former has been described in many families of Graeco-Italian ancestry: typically, the age of onset of parkinsonism in these families is $40-60$ but it is very variable and can include a dementia phenotype. The latter mutation has been described only in a single small family with parkinsonism. The mutations both cause synuclein to aggregate in model systems [3]. There are at least two, and probably more, genetic loci which lead to Lewy body disease, one on chromosome $2 \mathrm{p}$ and one on chromosome $4 p[7,8]$. 


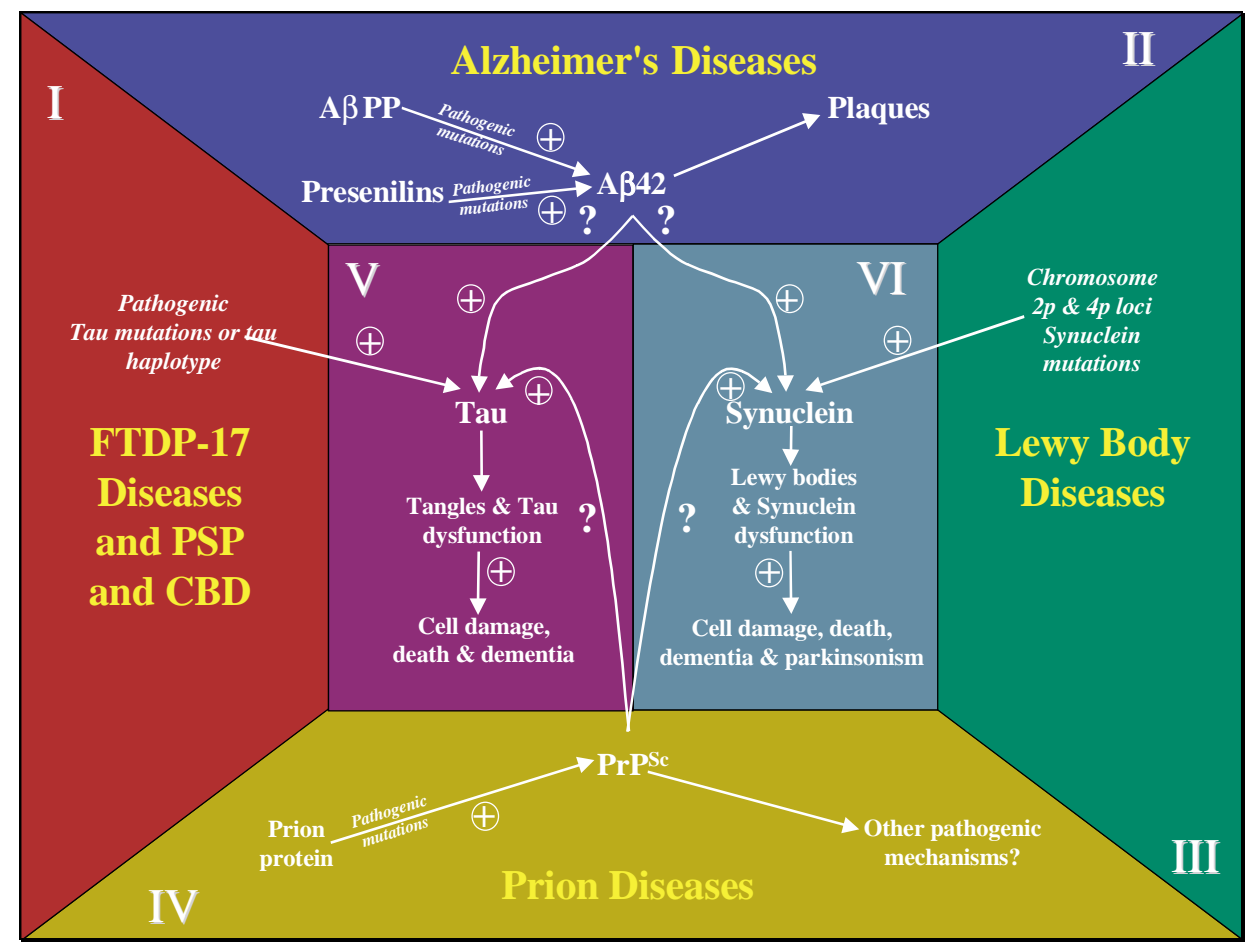

Fig. 7. Summary diagram linking all the tau and synucleinopathies is one broad framework of pathogenesis: note that (for example) this scheme is concordant both with the amyloid cascade hypothesis and with the notion that Alzheimer's disease is a tauopathy (adapted from [36]). Typical Alzheimer's disease is shown in boxes I, II and V: with Lewy bodies, VI etc. Worster Drought syndrome (British dementia) and Danish Dementia could also be fitted into this scheme as tauopathies [36,37] in the same way as prion diseases. It would be of interest in these disorders to look for Lewy bodies as they have not yet been described.

\section{The pathogenic relationships between the different tau and synucleinopathies}

A possible scheme illustrating plausible hierarchical relationships between the different pathologies is illustrated in Fig. 7. In this scheme, there are two broad pathways to cell death, one leading through tau and tangles and the other through synuclein and Lewy bodies. These pathways can either be triggered directly through mutations in their cognate genes, or either of them can be triggered (as alternatives to each other) by $\mathrm{A} \beta$ or by pathological prion protein [16]. Prediction of this hypothesis for Alzheimer's disease, which is an extension of the amyloid cascade hypothesis, are that reducing depositable $\mathrm{A} \beta$ should improve the clinical phenotype of Alzheimer's disease and that the amyloid and tau pathologies should interact. Both of these predictions are now being subject to test in transgenic animal models of disease ([31], M. Hutton and D. Morgan, personal communication).

\section{References}

[1] M. Baker, I. Litvan, H. Houlden, J. Adamson, D. Dickson and J. Hardy et al., Association of an extended haplotype in the tau gene with Progressive Supranuclear Palsy, Hum. Mol. Genet. 8 (1999), 711-715.

[2] A. Conrad, A. Andreadis, J.Q. Trojanowski, D.W. Dickson, D. Kang and X. Chen et al., Genetic evidence for the involvement of tau in progressive supranuclear palsy, Ann. Neurol. 41(2) (1997), 277-281.

[3] K.A. Conway, S.J. Lee, J.C. Rochet, T.T. Ding, R.E. Williamson and P.T. Lansbury Jr. et al., Acceleration of oligomerization, not fibrillization, is a shared property of both alpha-synuclein mutations linked to early-onset Parkinson's disease: implications for pathogenesis and therapy, Proc. Natl. Acad. Sci. USA 97(2) (2000), 571-576.

[4] P. Cras, F. van Harskamp, L. Hendriks, C. Ceuterick, C.M. van Duijn and S.Z. Stefanko et al., Presenile Alzheimer dementia characterized by amyloid angiopathy and large amyloid core type senile plaques in the APP 692Ala $\rightarrow$ Gly mutation, Acta Neuropathol. (Berl.) 96(3) (1998), 253-260.

[5] R. Crook, A. Verkkoniemi, J. Perez-Tur, N. Mehta, M. Baker and M. Farrer et al., A variant of Alzheimer's disease with spastic paraparesis and "cotton wool plaques" due to deletion of exon 9 of the presenilin 1 gene, Nature Medicine 4 (1998), $452-455$.

[6] B. De Strooper, W. Annaert, P. Cupers, P. Saftig, K. Craessaerts and J.S. Mumm et al., A presenilin-1-dependent gamma- 
secretase-like protease mediates release of Notch intracellular domain, Nature 398(6727) (1999), 518-522.

[7] M. Farrer, K. Gwinn-Hardy, M. Muenter, F. Wavrant DeVrieze, R. Crook and J. Perez-Tur et al., A chromosome 4p haplotype segregating with Parkinson's disease and postural tremor, Human Molecular Genetics 8(1) (1999), 81-85.

[8] T. Gasser, B. Muller-Myhsok, Z.K. Wszolek, R. Oehlmann, D.B. Calne and V. Bonifati et al., A susceptibility locus for Parkinson's disease maps to chromosome 2p13, Nat Genet. 18(3) (1998), 262-265.

[9] B. Ghetti, S.R. Dlouhy, G. Giaccone, O. Bugiani, B. Frangione, M.R. Farlow et al., Gerstmann - Straussler - Scheinker disease and the Indiana kindred, Brain Pathol. 1 (1995), 6175, Review.

[10] A. Goate, M.C. Chartier-Harlin, M. Mullan, J. Brown, F. Crawford and L. Fidani et al., Segregation of a missense mutation in the amyloid precursor protein gene with familial Alzheimer's disease, Nature 349(6311) (1991), 704-706.

[11] M. Goedert, M.G. Spillantini and S.W. Davies, Filamentous nerve cell inclusions in neurodegenerative diseases, Curr Opin Neurobiol. 8(5) (1998), 619-632, Review.

[12] A. Grover, H. Houlden, M. Baker, J. Adamson, S. PickeringBrown and M. Hutton, 5' Splice site mutations in tau associated with the inherited dementia FTDP-17 affect a stem-loop structure that regulates alternative splicing of exon 10, J. Biol. Chem. 274 (1999), 15134-15143.

[13] L.A. Hansen, E. Masliah, D. Galasko and R.D. Terry, Plaqueonly Alzheimer disease is usually the lewy body variant, and vice versa, J. Neuropathol. Exp. Neurol. 52(6) (1993), 648654.

[14] J. Hardy, Amyloid, The Presenilins and Alzheimer's Disease, Trends Neurosci. 20 (1997), 154-159.

[15] J. Hardy, K. Duff, K. Gwinn-Hardy, J. Perez-Tur and M. Hutton, Genetic dissection of Alzheimer's disease and related dementias: amyloid and its relationship to Tau, Nature Neuroscience 1 (1998), 355-358.

[16] J. Hardy, Pathways to Primary Neurodegenerative Disease, Mayo Clinic Proc. 74 (1999), 835-837.

[17] L. Hendriks, C.M. van Duijn, P. Cras, M. Cruts, W. Van Hul and F. van Harskampc et al., Presenile dementia and cerebral haemorrhage linked to a mutation at codon 692 of the betaamyloid precursor protein gene, Nat Genet. 1(3) (1992), 218221.

[18] H. Houlden, J. Collinge, A. Kennedy, S. Newman, M. Rossor and L. Lannfelt et al. ApoE Genotype and Alzheimer's Disease, Lancet 342 (1993), 737-738.

[19] M. Hutton, C.L. Lendon, P. Rizzu and the FTDP-17 Collaborative group, Association of missense and splice site mutations in tau with the inherited dementia FTDP-17, Nature 393 (1998), 702-705

[20] R. Kruger, W. Kuhn, T. Muller, D. Woitalla, M. Graeber and S. Kosel et al., Ala30Pro mutation in the gene encoding alphasynuclein in Parkinson's disease, Nat Genet. 18(2) (1998), 106-108.

[21] P.L. Lantos, I.M. Ovenstone, J. Johnson, C.A. Clelland, P. Roques and M.N. Rossor, Lewy bodies in the brain of two members of a family with the 717 (Val to Ile) mutation of the amyloid precursor protein gene, Neurosci Lett. 172(1-2) (1994), 77-79.

[22] D. Levitan and I. Greenwald, Facilitation of lin-12mediated signalling by sel-12, a Caenorhabditis elegans S182 Alzheimer's disease gene, Nature 377(6547) (1995), 351-354.

[23] E. Levy, M.D. Carman, I.J. Fernandez-Madrid, M.D. Power, I. Lieberburg and S.G. van Duinen et al., Mutation of the
Alzheimer's disease amyloid gene in hereditary cerebral hemorrhage, Dutch type, Science 248(4959) (1990), 1124-1126.

[24] E. Levy-Lahad, W. Wasco, P. Poorkaj, D.M. Romano, J. Oshima and W.H. Pettingell et al., Candidate gene for the chromosome 1 familial Alzheimer's disease locus, Science 18(269, 5226) (1995), 973-977.

[25] A.F. Lippa, H. Fujiwara, D.M. Mann, B. Giasson, M. Baba and M.L. Schmidt et al., Lewy bodies contain altered alphasynuclein in brains of many familial Alzheimer's disease patients with mutations in presenilin and amyloid precursor protein genes, Am. J. Pathol. 153(5) (1998), 1365-1370.

[26] J. Perez-Tur, S. Froelich, G. Prihar, R. Crook, M. Baker and K. Duff et al., A mutation in Alzheimer's disease destroying a splice acceptor site in the presenilin-1 gene, Neuroreport 7 (1995), 297-301.

[27] M.H. Polymeropoulos, C. Lavedan, E. Leroy, S.E. Ide, A. Dehejia and A. Dutra et al., Mutation in the alpha-synuclein gene identified in families with Parkinson's disease, Science 276(5321) (1997), 2045-2047.

[28] P. Poorkaj, T.D. Bird, E. Wijsman, E. Nemens, R.M. Garruto and L. Anderson, Tau is a candidate gene for chromosome 17 frontotemporal dementia, Ann. Neurol. 43(6) (1998), 815825.

[29] S.B. Prusiner, Prions, Proc. Natl. Acad. Sci. USA 95(23) (1998), 13363-13383, Review.

[30] L.M. Refolo, C. Eckman, C.M. Prada, D. Yager, K. Sambamurti and N. Mehta et al., Antisense-induced reduction of presenilin 1 expression selectively increases the production of amyloid $\beta 42$ in transfected calls, J. Neurochem 73(6) (1999), 2383-2388.

[31] D. Schenk, R. Barbour, W. Dunn, G. Gordon, H. Grajeda, T. Guido and K. et al., Immunization with amyloid-beta attenuates Alzheimer-disease-like pathology in the PDAPP mouse, Nature 400 (1999), 173-177.

[32] D. Scheuner, C. Eckman, M. Jensen, X. Song, M. Citron and N. Suzuki et al., Secreted amyloid $\beta$-protein similar to that in the senile plaques of Alzheimer's disease is increased in vivo by the presenilin 1 and 2 and APP mutations linked to familial Alzheimer's disease, Nature Medicine 2(8) (1996), 864-870.

[33] R. Sherrington, E.I. Rogaev, Y. Liang, E.A. Rogaeva, G. Levesque and M. Ikeda et al., Cloning of a gene bearing missense mutations in early-onset familial Alzheimer's disease, Nature 375(6534) (1995), 754-760.

[34] H. Steiner, K. Duff, A. Capell, H. Romig, M.G. Grim and S. Lincoln et al., A loss of function mutation of presenilin2 interferes with amyloid beta-peptide production and notch signaling, J. Biol. Chem. 274(40) (1999), 28669-28673.

[35] N. Suzuki, T.T. Cheung, X.-D. Cai, A. Odaka, L. Otvos, Jr. and C. Eckman et al., An increased percentage of long amyloid $\beta$ protein secreted by familial amyloid $\beta$ protein precursor ( $\beta$ APP717) mutants, Science 264 (1994), 1336-1340.

[36] R. Vidal, B. Frangione, A. Rostagno, S. Mead, T. Révész, G. Plant and J. Ghiso, A stop-codon mutation in the BRI gene associated with familial British dementia, Nature 399 (1999), 776-781.

[37] R. Vidal, T. Révész, A. Rostagno, E. Kim, J. Holton and T. Bek ET AL, A decamer duplication in the 3' region of the BRI gene originates a new amyloid peptide that is associated with dementia in a Danish kindred, Proc. Natl. Acad. Sci. USA 97 (2000), 4920-4925.

[38] M.S. Wolfe, W. Xia, B.L. Ostaszewski, T.S. Diehl, W.T. Kimberly and D.J. Selkoe, Two transmembrane aspartates in presenilin-1 required for presenilin endoproteolysis and gamma-secretase activity, Nature 398(6727) (1999), 513-517. 